\title{
Echocardiographic assessment for transcatheter aortic valve implantation
}

\section{Diana Rudan* \\ Josip Vincelj \\ Mira Stipčević \\ Sandra Jakšić Jurinjak \\ Jasmina Ćatić \\ Boris Starčević}

Dubrava University Hospital Zagreb, Croatia

\section{RECEIVED:}

April 14, 2015

ACCEPTED:

April 20, 2015

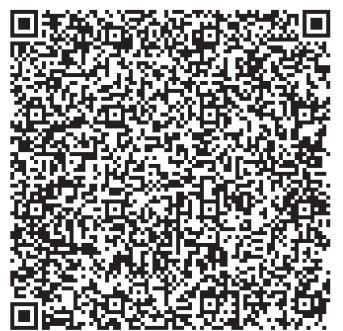

KEYWORDS: aortic stenosis, transcatheter aortic valve implantation, echocardiography

CITATION: Cardiol Croat. 2015;10(3-4):90. | DOI: http://dx.doi.org/10.15836/ccar.2015.90

ORCID: Diana Rudan, http://orcid.org/0000-0001-9473-2517 • Josip Vincelj, http://orcid.org/0000-0003-0064-9128 • Mira Stipčević, http://orcid.org/0000-0003-4351-1102 • Sandra Jakšić Jurinjak, http://orcid.org/0000-0002-7349-6137• Jasmina Ćatić, http://orcid.org/0000-0001-6582-4201 • Boris Starčević, http://orcid.org/0000-0002-3090-2772

*ADDRESS FOR CORRESPONDENCE: Diana Rudan, Klinička bolnica Dubrava, Avenija Gojka Šuška 6, HR-10000 Zagreb, Croatia. Phone: +385-91-333-7771. E-mail: drudan3@yahoo.com

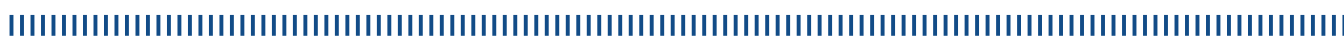

Surgical aortic valve replacement (AVR) is the conventional treatment for severe aortic stenosis (AS). Conservative management of patients with severe AS is known to have a poor prognosis and without surgery, the outcome of thiese patients is also extremely poor. However, with the aging of the population, the number of elderly patients with severe symptomatic aortic stenosis has grown, and a significant proportion of high-risk patients are not candidates for surgical aortic valve replacement because of age and comorbidities. Transcatheter aortic valve implantation (TAVI) was developed to address this unmet need. After the demonstration of feasibility of TAVI in 2002, it is now widely practiced, and the technique has been recommended as an alternative strategy for patients in high-risk surgical groups. ${ }^{1-4}$

An integrated approach with the use of multiple modalities for annular assessment is recommended because there are cases in which significant discrepancies in the measurements made using any 1 of the standard imaging techniques may exist.

However, echocardiography plays importante role in anatomical case selection, in procedural guidance, and in the management of complications. 2D and 3D transoesophageal echocardiography (TEE) enable detailed imaging of aortic valve (AV) and aortic root anatomy, measurement of AV annulus dimensions, and review of other cardiac and aortic structures. Measurement of the size of the aortic annulus requires precise assessment to allow appropriate valve selection and to minimize the risks of paravalvular leak and device migration. Standard 2D TEE techniques, with complementary 3D TEE imaging, are used in addition to fluoroscopy for intra-procedural guidance. Continuous real-time 2D and 3D TEE imaging enables the prompt detection, assessment, and management of complications, Comprehensive postprocedure TEE evaluation is performed following the initial confirmation of satisfactory transcatheter heart valve position and function.

In conclusion, echocardiography plays an essential role in the planning and provision of TAVI for high-risk patients with severe AV stenosis, and in combination with other imaging modalities, it allows appropriate case selection, correct choice of prosthetic size and type, guides successful implantation, and facilitates the treatment of complications.

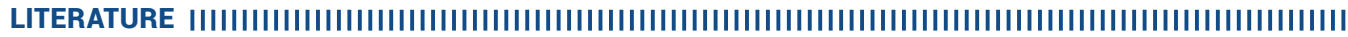

1. Faxon DP. Transcatheter aortic valve implantation: coming of age. Circulation. 2011;124(17):e439-e40. DOI: http://dx.doi.org/10.1161/CIRCULATIONAHA.111.065243

2. Al-Lamee R, Godino C, Colombo A. Transcatheter aortic valve implantation: current principles of patient and technique selection and future perspectives. Circ Cardiovasc Interv. 2011;4:387-95. DOI: http://dx.doi.org/10.116//CIRCINTERVENTIONS.111.961128

3. Chin D. Echocardiography for transcatheter aortic valve implantation. Eur J Echocardiogr. 2009:10(1):i21-9. DOI: http://dx.doi.org/10.1093/ejechocard/jen245

4. Smith LA, Monaghan MJ. Monitoring of procedures: peri-interventional echo assessment for transcatheter aortic valve implantation. Eur Heart J Cardiovasc Imaging. 2013;14(9):840-50. DOI: http://dx.doi.org/10.1093/ehjci/jet042 